\title{
Comparative Study of Outcome of Open Vs Closed Hemorrhoidectomy Vs Rubber Band Ligation in Third Degree Haemorrhoids
}

\author{
* Rajasekar $\mathbf{M}^{1}$ Jasmine $^{2}$ \\ ${ }^{l}$ associate Professor, Department Of General Surgery, Government Mohan Kumaramangalam \\ Medical College, Salem. \\ ${ }^{2}$ post Graduate Student, Department Of General Surgery, Government Mohan Kumaramangalam \\ Medical College, Salem.
}

\begin{abstract}
Haemorrhoids is one of the most common problem that a Surgeon faces in his day to day practice. The diagnosis of hemorrhoids is clinched by clinical and proctoscopic examination. The disease is graded based on bleeding or mass descending per rectum and treated accordingly. Grade III hemorrhoids are prolapsed masses that do not reduce spontaneously and reuire digital reposition. This study compares the efficacy of three procedures namely open hemorrhoidectomy and Rubber Band Ligation(RBL) in the treatment of third degree Hemorrhoids in the subjects presenting to the surgical out patient department of GMKMCH, Salem, Tamilnadu. This study was conducted in 75 random cases of third degree hemorrhoids over a period ofone and half years from Dec 2012 to Aug 2014. Out of 75 cases, 225 cases were subjected to open hemorrhoidectomy, 25 cases to closed hemorrhoidectomy and 25 cases to RBL, after obtaining written consent and a prior proctoscopic examination to rule out other associated diseases of the rectum and anal canal. Patients with other associated diseases like malignancy, fissure were excluded from the study. All parameters were recorded and analysed finally using SPSS statistical package. Hemorrhoidectomy achieves slightly better results than RBL in the management of third degree haemorrhoids. However RBL, being an outpatient procedure, can be easily applied on patients unfit for spinal anaesthesia and those with bleeding disorders. Hence RBL could be recommended in those patients in whom anaesthesia is contraindicated. Ultimately open hemorrhoidectomy achieves better results than RBL in the treatment of third degree haemorrhoids.
\end{abstract}

Keywords: RBL, Hemorrhoidectomy, Proctoscopic examination.

\section{Introduction}

Haemorrhoids affecting people had been known since time immemorial. The erect posture assumed by the humans had been told as a risk factor to develop haemorrhoids. Haemorrhoids are normal anatomical structures, that can be demonstrated even in babies. ${ }^{6}$ They most commonly become pathological when the intra abdominal pressure is raised eg: in obesity, constipation and pregnancy. ${ }^{1}$ It results from pathological changes in the prolapsed anal column. ${ }^{6}$ It had been estimated that $5 \%$ of the general population is affected by the symptoms of haemorrhoids. ${ }^{7}$ Haemorrhoids identification and treatment is very important that many other pathological states may mimic haemorrhoids and hence careful evaluation becomes mandatory. The most common symptoms of haemorrhoids include bright red bleeding and mass descending per rectum. Patients are assessed clinically by Digital Rectal Examination and by anoscopy in the left lateral position. The haemorrhoidal cushions are viewed in the left lateral, right anterior and posterior positions as 3, 7, 11 O' clock positions in the Lithotomy position. Sigmoidoscopic examination may be required to rule out any rectal disease, if suspected. The treatment for Haemorrhoids is classified into three categories according to the guidelines laid down by the American Society of Colon and Rectal Surgeons. ${ }^{8}$ a)Conservative management comprising of dietary fibres and avoiding constipation. Sitz bath with astringents for short term relief. b)Minimally invasive procedures like RBL. ${ }^{9}$ c)Injection sclerotherapy. ${ }^{10}$ d)Infrared coagulation and cryosurgery. ${ }^{11}$ e)Surgical haemorrhoidectomy. ${ }^{12,13}$ f)Doppler guided Haemorrhoidal artery ligation. ${ }^{14}$ g)LASER haemorrhoidectomy. ${ }^{15}$ Haemorrhoidectomy was considered to be the optimal form of treatment for haemorrhoids, a few decades ago. Now a days, other modalities such as medical management, Rubber band ligation, sclerotherapy, cryosurgery are all being used widely. RBL is the most commonly used non operative method of cure for haemorrhoids because of its efficacy and minor complication rate with its shorter recovery time compared to the surgical procedure. ${ }^{16}$ The success rate of RBL in different studies varies from $69-97 \%{ }^{17-19}$. Though haemorrhoidectomy had been the procedure of choice for haemorrhoids, now a days this procedure is reserved for patients presenting with prolapsed pile mass ( grade III Haemorrhoids) and in those with thrombosed external haemorrhoids. Most of all the other patients are treated with either conservative or non operative management. Though surgery is the most definitive treatment of all modalities, it is such a painful procedure to 
be tolerated for a relatively benign disease with adverse effects on the anal canal physiology. ${ }^{20}$ My study visualises and compares the efficacy and complication rates associated with three modalities of haemorrhoidal management namely Open Haemorrhoidectomy, Closed Haemorrhoidectomy and Rubber Band Ligation.

\section{Objectives}

To assess and compare the efficacy and outcome of closed haemorrhoidectomy, open haemorrhoidectomy and rubber band ligation in the treatment of haemorrhoids.

To compare the complications associated.

To decide on the better treatment for grade III Haemorrhoids based on the findings of the study.

\section{Materials And Methods}

This study was conducted in Government Mohan Kumaramangalam Medical College Hospital, Salem from December 2012 to August 2014.CASE SELECTION: The study population consists of patients presenting in the General Surgical out patient department with complaints of bleeding PR/mass descending PR and diagnosed as a case of third degree haemorrhoids at Government Mohan Kumaramangalam Medical College Hospital, Salem.

Inclusion Criteria: All patients who presented to the surgical out patient department with complaints of bleeding per rectum or mass descending per rectum diagnosed as Grade III Haemorrhoids were included in the study.

Exclusion Criteria: 1.Grade I, II, IV Haemorrhoids.2.Patients not willing for treatment.3.Patients with other complex lower GI problems like fistula in ano, malignancy. 4.Patients losing follow up were excluded from the study.

Method Of Collection Of Data: Patients coming to the out patient department of Govt Mohan Kumaramangalam Medical College Hospital with complaints of bleeding and mass descending per rectum were subjected to detailed history taking and examination that includes the symptomatology of the disease. After digital rectal examination patients are subjected to proctoscopic examination to confirm the diagnosis and to rule out other associated conditions. Systemic examination and basic investigations were done. Patijents were randomly subjected to open haemorrhoidectomy, closed haemorrhoidectomy and rubber band ligation after getting written informed consent for the study. Follow up of these patients were done with history and digital rectal examination and rate of complications like pain, bleeding, ulceration, stenosis and recurrence were assessed for a time period of six months.

Sample Size: Among the 75 patients who were diagnosed to have grade III Haemorrhoids were randomly grouped into three categories.Group 1: 25 patients were subjected to open haemorrhoidectomy. Group 2: 25 patients were subjected to closed haemorrhoidectomy. Group 3: 25 patients were subjected to rubber band ligation.

Follow Up: Patients were followed up till the fifth post operative day,and then weekly for the first month and then once every month for the next five months.

\section{Results}

A total of 75 cases who presented to the surgical out patient department in Govt Mohan Kumaramangalam Medical College Hospital, Salem during the one and a half year study period were enrolled in the study. The subjects were thoroughly examined and subjected randomly to open hemorrhoidectomy, closed hemorrhoidectomy and rubber band ligation. This was summarised into a master chart. The collected data was analysed with SPSS 16.0 version. The comparable tabulations permit certain statistical inferences to be made which are presented below.

Table - 1 Age Incidence

\begin{tabular}{|l|l|l|}
\hline Age in years & Number of cases & Percentage \\
\hline $11-20$ & 02 & 2.7 \\
\hline $21-30$ & 14 & 18.7 \\
\hline $31-40$ & 13 & 17.3 \\
\hline $41-50$ & 25 & 33.3 \\
\hline $51-60$ & 07 & 18.7 \\
\hline $61-75$ & 14 & 9.3 \\
\hline Total & $\mathbf{7 5}$ & $\mathbf{1 0 0 . 0}$ \\
\hline
\end{tabular}

The age of the patients varied from 19 years to 71 years. Maximum number of patients were in the age group of 41 to 50 years. The following table shows the age distribution in the study group. 
Table - 2 Sex Incidence

\begin{tabular}{|l|l|l|}
\hline Sex & Number Of Cases & Percentage \\
\hline Male & 54 & 72.0 \\
\hline Female & 21 & 28.0 \\
\hline Total & $\mathbf{7 5}$ & $\mathbf{1 0 0 . 0}$ \\
\hline
\end{tabular}

Out of 75 cases, 54 were males and 21 were females. There is a male preponderance among patients in this study.

Table-3 Distribution Of Symptoms In All Cases

\begin{tabular}{|l|l|l|}
\hline Presenting complaints & Cases & \% \\
\hline Bleeding, mass descending pr and painful defecation & 49 & 65.33 \\
\hline Bleeding and mass descending pr & 18 & 24.00 \\
\hline Mass descending pr and painful defecation & 04 & 5.33 \\
\hline Mass descending pr & 04 & 5.33 \\
\hline Total & $\mathbf{7 5}$ & $\mathbf{1 0 0 . 0}$ \\
\hline
\end{tabular}

The presenting complaints in all 75 patients are tabulated in Table 03.The presenting complaint in almost $65.33 \%$ of patients was bleeding per rectum, mass descending per rectum and painful defecation. Since, grade III haemorrhoids is where the mass descending per rectum reduces only on digital reposition, all patients included in the study had history of mass descending per rectum. $24 \%$ of patients presented with bleeding and mass descending per rectum and $4 \%$ of patients presented with mass descending per rectum and painful defecation and another $4 \%$ presented with all three symptoms bleeding and mass descending per rectum and painful defecation together. Hence, by observation in the study, the most common symptomatology of grade III haemorrhoids is mass descending per rectum and bleeding per rectum. Painful defecation may or may not be associated

Table-4 Type Of Treatment

\begin{tabular}{|l|l|l|}
\hline Type Of Surgery & Cases & \% \\
\hline Open Hemorrhoidectomy & 25 & 33.3 \\
\hline Closed Hemorrhoidectomy & 25 & 33.3 \\
\hline Rubber Band Ligation & 25 & 33.3 \\
\hline Total & $\mathbf{7 5}$ & $\mathbf{1 0 0 . 0}$ \\
\hline
\end{tabular}

All patients were randomly subjected to three groups. Out of 75 patients, 25 were subjected to open hemorrhoidectomy, 25 to closed hemorrhoidectomy and the other 25 were subjected to rubber band ligation.

Table-5 Type Of Anaesthesia

\begin{tabular}{|l|l|l|l|l|l|l|l|l|}
\hline \multirow{2}{*}{$\begin{array}{l}\text { Type of } \\
\text { anaesthesia }\end{array}$} & $\begin{array}{l}\text { Closed } \\
\text { hemorrhoidectomy }\end{array}$ & \multicolumn{2}{|l|}{$\begin{array}{l}\text { Open } \\
\text { hemorrhoidectomy }\end{array}$} & \multicolumn{2}{l|}{$\begin{array}{l}\text { Rubber } \\
\text { ligation }\end{array}$} & \multicolumn{2}{|c|}{ band } & \multicolumn{2}{|l|}{ Total } \\
\cline { 2 - 10 } & No of cases & $\%$ & No of cases & $\%$ & $\begin{array}{l}\text { No of } \\
\text { cases }\end{array}$ & $\%$ & $\begin{array}{l}\text { No of } \\
\text { cases }\end{array}$ & $\%$ \\
\hline Local anaesthesia & 0 & $0.0 \%$ & 0 & $0.0 \%$ & 24 & $32.0 \%$ & 24 & $32.0 \%$ \\
\hline Spinal anaesthesia & 25 & $33.3 \%$ & 25 & $33.3 \%$ & 1 & $1.3 \%$ & 51 & $68.0 \%$ \\
\hline
\end{tabular}

Out of 75 cases, all 50 cases subjected to open and closed hemorrhoidectomy were operated under spinal anaesthesia whereas out of all patients who underwent rubber band ligation only one patient had spinal anaesthesia and rest of the 24 were treated under local anaesthesia.

Table-6 Post Operative Stay

\begin{tabular}{|l|l|l|l|l|l|l|l|l|}
\hline \multirow{2}{*}{$\begin{array}{l}\text { Post operative } \\
\text { stay }\end{array}$} & $\begin{array}{l}\text { Closed } \\
\text { hemorrhoidectomy }\end{array}$ & \multicolumn{2}{l|}{$\begin{array}{l}\text { Open } \\
\text { hemorrhoidectomy }\end{array}$} & $\begin{array}{l}\text { Rubber } \\
\text { ligation }\end{array}$ \\
\cline { 2 - 10 } & $\begin{array}{l}\text { No of } \\
\text { cases }\end{array}$ & $\begin{array}{l}\text { No of } \\
\text { cases }\end{array}$ & $\%$ & No of cases & $\%$ & No of cases & \% \\
\hline One day & 0 & $0.0 \%$ & 0 & $0.0 \%$ & 25 & $33.3 \%$ & $\mathbf{2 5}$ & \multicolumn{2}{l|}{ TOTAL } \\
\hline Two days & 1 & $1.3 \%$ & 0 & $0.0 \%$ & 0 & $0.0 \%$ & $\mathbf{1}$ & $\mathbf{1 . 3 \%}$ \\
\hline Three days & 9 & $12.0 \%$ & 13 & $17.3 \%$ & 0 & $0.0 \%$ & $\mathbf{2 2}$ & $\mathbf{2 9 . 3 \%}$ \\
\hline Four days & 0 & $0.0 \%$ & 4 & $5.3 \%$ & 0 & $0.0 \%$ & $\mathbf{4}$ & $\mathbf{5 . 3 \%}$ \\
\hline
\end{tabular}


Comparative Study Of Outcome Of Open Vs Closed Hemorrhoidectomy Vs Rubber Band

\begin{tabular}{|l|l|l|l|l|l|l|l|l|}
\hline Five days & 15 & $20.0 \%$ & 7 & $9.3 \%$ & 0 & $0.0 \%$ & $\mathbf{2 2}$ & $\mathbf{2 9 . 3 \%}$ \\
\hline Eight days & 0 & $0.0 \%$ & 1 & $1.3 \%$ & 0 & $0.0 \%$ & $\mathbf{1}$ & $\mathbf{1 . 3 \%}$ \\
\hline TOTAL & $\mathbf{2 5}$ & $\mathbf{3 3 . \%}$ & $\mathbf{2 5}$ & $\begin{array}{l}\mathbf{3 3 . 3} \\
\boldsymbol{\%}\end{array}$ & $\mathbf{2 5}$ & $\begin{array}{l}\mathbf{3 3 . 3} \\
\boldsymbol{\%}\end{array}$ & $\begin{array}{l}\mathbf{7 5} \\
\mathbf{\%}\end{array}$ \\
\hline
\end{tabular}

Out of all 75 cases, those patients who underwent rubber band ligation had to stay in the hospital for one day only and those who underwent hemorrhoidectomy had to stay from a minimum of 3 days to the maximum of 8 days.

Table-7 Post Operative Pain In All Three Groups

\begin{tabular}{|l|l|l|l|l|l|l|}
\hline \multirow{2}{*}{$\begin{array}{l}\text { Post } \text { Pain } \\
\end{array}$} & \multicolumn{2}{|l|}{ Operative } & \multicolumn{2}{l|}{$\begin{array}{l}\text { Open } \\
\text { hemorrhoidectomy }\end{array}$} & \multicolumn{2}{l|}{ Rubber band ligation } \\
\cline { 2 - 7 } & No of cases & $\mathbf{\%}$ & No of cases & $\mathbf{\%}$ & No of cases & \% \\
\hline Painful & 11 & $14.7 \%$ & 9 & $12.0 \%$ & 2 & $2.7 \%$ \\
\hline Painless & 14 & $16.0 \%$ & 16 & $18.7 \%$ & 23 & $31.3 \%$ \\
\hline TOTAL & $\mathbf{2 5}$ & $\mathbf{3 3 . 3} \%$ & $\mathbf{2 5}$ & $\mathbf{3 3 . 3 \%}$ & $\mathbf{2 5}$ & $\mathbf{3 3 . 3 \%}$ \\
\hline
\end{tabular}

Table-8 Post Operative Bleeding Per Rectum

\begin{tabular}{|c|c|c|c|c|c|c|}
\hline \multirow[t]{2}{*}{$\begin{array}{l}\text { Post operative } \\
\text { Bleeding per rectum }\end{array}$} & \multicolumn{2}{|c|}{$\begin{array}{l}\text { Closed } \\
\text { hemorrhoidectomy }\end{array}$} & \multicolumn{2}{|c|}{$\begin{array}{l}\text { Open } \\
\text { hemorrhoidectomy }\end{array}$} & \multicolumn{2}{|c|}{ Rubber band ligation } \\
\hline & No of cases & $\%$ & No of cases & $\%$ & No of cases & $\%$ \\
\hline Present & 3 & $4.0 \%$ & 2 & $2.7 \%$ & 0 & $0.0 \%$ \\
\hline Absent & 22 & $29.3 \%$ & 23 & $30.7 \%$ & 25 & $33.3 \%$ \\
\hline TOTAL & 25 & $33.3 \%$ & 25 & $33.3 \%$ & 25 & $33.3 \%$ \\
\hline
\end{tabular}

Table-9 Ulceration Of Perianal Skin

\begin{tabular}{|l|l|l|l|l|l|l|}
\hline \multirow{2}{*}{$\begin{array}{l}\text { Ulceration of the } \\
\text { perianal skin }\end{array}$} & \multicolumn{2}{|l|}{ Closed hemorrhoidectomy } & \multicolumn{2}{l|}{ Open hemorrhoidectomy } & \multicolumn{2}{l|}{ Rubber band ligation } \\
\cline { 2 - 7 } & No of cases & $\mathbf{\%}$ & No of cases & \% & No of cases & \% \\
\hline Present & 0 & $0.0 \%$ & 2 & $2.7 \%$ & 5 & $6.7 \%$ \\
\hline Absent & 25 & $33.3 \%$ & 23 & $30.7 \%$ & 20 & $26.7 \%$ \\
\hline TOTAL & $\mathbf{2 5}$ & $\mathbf{3 3 . 3 \%}$ & $\mathbf{2 5}$ & $\mathbf{3 3 . 3 \%}$ & $\mathbf{2 5}$ & $\mathbf{3 3 . 3 \%}$ \\
\hline
\end{tabular}

From the above table it is evident that, Out of 25 patients who underwent open hemorrhoidectomy, $2.7 \%$ of patients had ulceration of the perianal skin post operatively.Out of 25 patients who underwent rubber band ligation, $6.7 \%$ of patients presented with ulceration of the perianal skin. None of the patients who underwent closed hemorrhoidectomy did present with ulceration.

Table -10 Post Operative Anal Stenosis

\begin{tabular}{|l|l|l|l|l|l|l|}
\hline Post operative Anal Stenosis & $\begin{array}{l}\text { Closed } \\
\text { hemorrhoidectomy }\end{array}$ & \multicolumn{2}{l|}{$\begin{array}{l}\text { Open } \\
\text { hemorrhoidectomy }\end{array}$} & \multicolumn{2}{l|}{ Rubber band ligation } \\
\cline { 2 - 7 } & No of cases & $\%$ & $\begin{array}{l}\text { No of } \\
\text { cases }\end{array}$ & No of cases & $\%$ \\
\hline Present & 1 & $1.3 \%$ & 3 & $4.0 \%$ & 0 & $0.0 \%$ \\
\hline Absent & 24 & $32.0 \%$ & 22 & $29.3 \%$ & 25 & $33.3 \%$ \\
\hline TOTAL & $\mathbf{2 5}$ & $\mathbf{3 3 . 3} \%$ & $\mathbf{2 5}$ & $\mathbf{3 3 . 3 \%}$ & $\mathbf{2 5}$ & $\mathbf{3 3 . 3} \%$ \\
\hline
\end{tabular}

From

the above table it is evident that, Out of 25 patients who underwent open hemorrhoidectomy, $4.0 \%$ of patients had anal stenosis post operatively. Out of 25 patients who underwent closed hemorrhoidectomy, $1.3 \%$ of patients had anal stenosis post operatively. None of the patients who underwent rubber band ligation did present with anal stenosis post operatively.

Table-11 Post Operative Recurrence

\begin{tabular}{|l|l|l|l|l|l|l|}
\hline \multirow{2}{*}{$\begin{array}{l}\text { Post operative } \\
\text { Recurrence }\end{array}$} & \multicolumn{2}{|l|}{ Closed hemorrhoidectomy } & \multicolumn{2}{l|}{ Open hemorrhoidectomy } & \multicolumn{2}{l|}{ Rubber band ligation } \\
\cline { 2 - 7 } & No of cases & $\mathbf{\%}$ & No of cases & $\%$ & No of cases & \% \\
\hline Present & 2 & $2.7 \%$ & 0 & $0.0 \%$ & 2 & $2.7 \%$ \\
\hline Absent & 23 & $30.7 \%$ & 25 & $33.3 \%$ & 23 & $30.7 \%$ \\
\hline TOTAL & $\mathbf{2 5}$ & $\mathbf{3 3 . 3} \%$ & $\mathbf{2 5}$ & $\mathbf{3 3 . 3} \%$ & $\mathbf{2 5}$ & $\mathbf{3 3 . 3 \%}$ \\
\hline
\end{tabular}


From the above table it is evident that, Out of 25 patients who underwent closed hemorrhoidectomy, $2.7 \%$ of patients had recurrence post operatively. Out of 25 patients who underwent rubber band ligation, $2.7 \%$ of patients presented with recurrence. None of patients who underwent open hemorrhoidectomy did present with recurrence post operatively.

Table- 12 complications Related To All The Three Modalities Of Treatment

\begin{tabular}{|c|c|c|c|c|c|c|}
\hline \multirow[t]{2}{*}{ Complications } & \multicolumn{2}{|c|}{$\begin{array}{l}\text { Closed } \\
\text { Hemorrhoidectomy }\end{array}$} & \multicolumn{2}{|c|}{$\begin{array}{l}\text { Open } \\
\text { Hemorrhoidectomy }\end{array}$} & \multicolumn{2}{|c|}{ Rubber Band Ligation } \\
\hline & No Of Cases & $\%$ & No Of Cases & $\%$ & No Of Cases & $\%$ \\
\hline Pain & 11 & $14.7 \%$ & 9 & $12.0 \%$ & 2 & $2.7 \%$ \\
\hline Bleeding & 3 & $4.0 \%$ & 2 & $2.7 \%$ & $\mathbf{0}$ & $0.0 \%$ \\
\hline Ulceration & 0 & $0.0 \%$ & 2 & $2.7 \%$ & 5 & $6.7 \%$ \\
\hline Stenosis & 1 & $1.3 \%$ & 3 & $4.0 \%$ & $\mathbf{0}$ & $0.0 \%$ \\
\hline Recurrence & 2 & $2.7 \%$ & $\mathbf{0}$ & $0.0 \%$ & 2 & $2.7 \%$ \\
\hline
\end{tabular}

Closed hemorrhoidectomy led to higher chance of anal stenosis, lead to recurrence in few cases and was reported by patients as painful for at least 4 weeks and compelled the usage of analgesics. Open hemorrhoidectomy, being the procedure of choice in grade III hemorrhoids, had no recurrence, whereas pain, bleeding and stenosis significantly decreased the quality of life in affected patients. Rubber band ligation, most accepted by patients, if offered as a treatment modality, left no residual post procedural effects on the patients, but, lead to recurrence in few patients.

\section{Discussion}

Haemorrhoids is the most common surgical disease that a surgeon faces in his day to day practice. Al though haemorrhoids is not life threatening, it causes discomfort to the patient each time he defecates. Hence, it deserves careful examination and management. Various studies that have analysed the different modalities of treatment of haemorrhoids, but there had never been a perfect technique described for this disease.$^{20}$ Surgical hemorrhoidectomy is the most commonly performed procedure to treat haemorrhoids. However, it is associated with highest complication rate and causes a significant change in the coordination of anorectal physiology, when compared to all other techniques. ${ }^{15}$ however, it is claimed to be the procedure of choice in patients who did not respond to office procedures like rubber band ligation and cryosurgery and in those with prolapsed haemorrhoids. ${ }^{21}$ Rubber band ligation is also widely practised because of its safety and efficacy as an out patient procedure in treating patients with haemorrhoids. It causes lesser post operative pain and bleeding and causes a quicker recovery. Since haemorrhoids is a benign condition, we tried a less invasive procedure that caused least discomfort to the patient and highly accepted by patients. For this reason, we performed rubber band ligation for grade III haemorrhoids patients. Our study consisting of patients with grade III haemorrhoids analysed the symptomatology and efficacy post treatment. In our study, the incidence of patients with haemorrhoids was the highest in the 4 th decade. According to this study, haemorrhoids predominates in males (54\%). The most common symptomatology of this disease being bleeding and mass descending per rectum along with painful defecation in $65.33 \%$ of cases. Although mass descending per rectum stands as the singlemost symptom that is present in almost all cases. According to a meta analytic study conducted by Mac Ray HM et al, in the year 1995, hemorrhoidectomy was associated with more post operative complications than rubber band ligation. In our study comparison was done between open and closed hemorrhoidectomy and rubber band ligation, and we found that surgical hemorrhoidectomy was associated with high bleeding rate and higher incidence of pain and stenosis. And recurrence rate was only about $2.7 \%$ in the banding group, which is comparable with the results of a previous study conducted by Muhammad ifshar et al in the year 2012 and 2013 found a recurrence rate of $3 \%$ with banding. But, none of the patients with open hemorrhoidectomy recurred in our study.

\section{Conclusion}

Rubber band ligation is a simple, effective and safe out patient procedure that can be advocated in patients with grade III haemorrhoids. It requires very simple instrumentation and is cost effective. It is easily accepted by patients and has minimal post operative complications. But, recurrence is a limiting factor and long term results are poorer when compared to hemorrhoidectomy. Open hemorrhoidectomy gives best long term results with almost no recurrence in our study whereas the immediate post operative effects are cumbersome to the patients when compared to rubber band ligation. Its disadvantage include increased post operative stay, longer recovery time, high incidence pain and bleeding per rectum. Closed hemorrhoidectomy is also another surgical procedure that gives best long term results, but post operative pain is higher compared to open hemorrhoidectomy and that it leads to late anal canal stenosis in some individuals. Considering all the above factors, rubber band ligation is both safe and effective in patients with grade III haemorrhoids with lesser hospital stay and quicker recovery time and with minimal post operative complications. And hence patient 
acceptance is better in this treatment modality. Given all these advantages and disadvantages, it can be concluded that, Rubber band ligation is efficacious in the treatment of third degree haemorrhoids, when compared to Open or Closed Hemorrhoidectomy.

\section{References}

[1]. Bailey and Love short practice of surgery $26^{\text {th }}$ edition

[2]. Skandalaki's - Surgical Anatomy

[3]. Gray H: Anatomy of human body.

[4]. Mastery of surgery by Fischer $-6^{\text {th }}$ edition

[5]. Current surgical therapy, Cameron, $11^{\text {th }}$ ed, chapter on large bowel, pgs: 255-61

[6]. Thomson WH (1975) The nature of Hemorrhoids. BJS 62: $542-52$

[7]. Scneider. EB, Maykel JA. Diagnosis and management of symptomatic haemorrhoids. Surg Clin North Am. $2010 ; 90$ (1) : 17-32.

[8]. American society of Colon and Rectal Surgeons (1993) Practice parameters for the treatment of Hemorrhoids. Dis Colon Rectum 36: $1118-20$.

[9]. Barron J (1963) Office ligation treatment of haemorrhoids. Dis Colon Rectum 6: 109-113

[10]. Sato SG, Novell JR, Khowry G, Winslet MC, Lewis A (1993) Long term results of large dose, single session phenol injection sclerotherapy for Hemorrhoids. Dis Colon Rectum 36: 958-91

[11]. Buls JG, Goldberg SM (1978) Modern management of Hemorrhoids. Surg Clin North Am. 58: 469

[12]. Ferguson JA, Mazier WP, Ganchrow MI, Freind WG (1971) The closed technique of hemorrhoidectomy. Surgery 70: 480

[13]. Rowsell M, Bellow M, Hemingway DM (2000). Circumferential mucosectomy (stapled hemorrhoidectomy) vs conventional hemorrhoidectomy : RCT. Lancet 355: 779.

[14]. Moringa K, Hasuda K, Ideda T et al(1995) A novel therapy for internal haemorrhoids: ligation of the hemorrhoidal artery with a newly devised instrument (Moricorn) in conjunction with a Doppler flowmeter. Am J Gastroenterol 90:610

[15]. Hodgson WJ, Morgan J(1995). Ambulatory Hemorrhoidectomy with $\mathrm{CO}_{2}$ LASER. Dis Colon Rectum 38 : 1265.

[16]. MacRae HM, MC Leod RS. Comparison of hemorrhoidal treatment modalities. A meta analysis. Dis Colon Rectum 1995; 38(7): 687-94

[17]. Keighley MR. RCT to sompare photocoagulation with RBL for treatment of haemorrhoids. Proctol $1982 ; 4: 132-34$

[18]. Marshman D, Timmerman W et al. Hemorrhoidal ligation: a review of efficiency Dis Colon Rectum $1989 ; 32: 369-77$.

[19]. Clay LD III, White JJ, Davidson JT, Chandler JJ. Early recognition and successful management of pelvic cellulitis following Hemorrhoidal banding. Dis Colon Rectum $1986 ; 29: 579-81$

[20]. El Nakeeb AM et al. RBL for 750 cases of symptomatic haemorrhoids out of 2200 cases. World J Gastroenterol. 2008; 14(42): 6525-30.

[21]. Rivadeneira DE, Steele SR et al. Practice parameters for the management of haemorrhoids (revised 2010). Dis Colon Rectum.2011:54(9): 1059-64. 